\title{
New concepts for dynamic plant uptake models
}

\author{
Rein, Arno; Legind, Charlotte Nielsen; Trapp, Stefan
}

Published in:

S A R and Q S A R in Environmental Research

Link to article, DOI:

$10.1080 / 1062936 X .2010 .548829$

Publication date:

2011

Document Version

Early version, also known as pre-print

Link back to DTU Orbit

Citation (APA):

Rein, A., Legind, C. N., \& Trapp, S. (2011). New concepts for dynamic plant uptake models. S A R and Q S A R in Environmental Research, 22(1-2), 191-215. https://doi.org/10.1080/1062936X.2010.548829

\section{General rights}

Copyright and moral rights for the publications made accessible in the public portal are retained by the authors and/or other copyright owners and it is a condition of accessing publications that users recognise and abide by the legal requirements associated with these rights.

- Users may download and print one copy of any publication from the public portal for the purpose of private study or research.

- You may not further distribute the material or use it for any profit-making activity or commercial gain

- You may freely distribute the URL identifying the publication in the public portal

If you believe that this document breaches copyright please contact us providing details, and we will remove access to the work immediately and investigate your claim. 


\section{New Concepts for Dynamic Plant Uptake Models}

Running title:

Dynamic Plant Uptake Models

Arno Rein $^{a}{ }^{*}$, Charlotte N. Legind ${ }^{b}$ and Stefan Trapp ${ }^{c}$

Department of Environmental Engineering, Technical University of Denmark, Miljøvej, Bd. 113, DK-2800 Kgs. Lyngby, Denmark,

a Phone: +45 4525-1696, Fax: +45 4593 2850, Email: arnr@env.dtu.dk

${ }^{\text {b }}$ Phone: +45 4525-1588, Fax: +45 4593 2850, Email: chanl@env.dtu.dk

${ }^{\mathrm{c}}$ Phone: +45 4525-1622, Fax: +45 4593 2850, Email: stt@env.dtu.dk

* Corresponding author 


\begin{abstract}
Models for the prediction of chemical uptake into plants are widely applied tools for human and wildlife exposure assessment, pesticide design and for environmental biotechnology such as phytoremediation. Steady-state considerations are often applied, because they are simple and have a small data need. However, often the emission pattern is non-steady. Examples are pesticide spraying, or the application of manure and sewage sludge on agricultural fields. In these scenarios, steady-state solutions are not valid, and dynamic simulation is required.

We compared different approaches for dynamic modelling of plant uptake in order to identify relevant processes and time-scales of processes in the soil-plant-air system. Based on the outcome, a new model concept for plant uptake models was developed, approximating logistic growth and coupling transpiration to growing plant mass. The underlying system of differential equations was solved analytically for the inhomogenous case, i.e., for constant input. By superposition of the results of $\mathrm{n}$ periods, changes in emission and input data between periods are considered. This combination allows to mimick most input functions that are relevant in practice. The model was set up, parameterised and tested for uptake into growing crops. The outcome was compared to a numerical solution, to verify the mathematical structure.
\end{abstract}

\title{
Keywords
}

plant uptake; modelling; dynamic; steady-state; analytical solution; plant growth 


\section{Introduction}

Models for the prediction of chemical uptake into plants are widely applied tools for human exposure assessment in chemical risk assessment, in pesticide design, in impact assessment of soil and air pollution and for environmental biotechnology such as phytoremediation [1-3]. Steady-state considerations are often applied, because they are simple and have a small data need. However, often the emission pattern is non-steady. Examples are pesticide spraying, or the application of manure and sewage sludge on agricultural fields. In these scenarios, steady-state solutions are not appropriate, and dynamic simulations are superior. Furthermore, many environmental conditions are characterised by dynamic processes and may show daily or annual cycles. The objectives of this paper are to investigate the consequences of different emission and plant growth patterns on the required model structure and to find a suitable solution that describes most of the dynamics of the system with acceptable efforts.

There is a dispute going on whether steady-state solutions are sufficient, or whether dynamic models should be developed [4-5]. Undeman and co-workers [5] evaluated the dynamic behaviour of compounds in the soil-plant-air system and found that, in case of rapid growth of plants, steady-state would always be approached within the growth time of plants. According to these findings, steady-state solutions would be valid, at least under certain conditions. Steadystate solutions of differential equation systems have the clear advantage of being comparatively simple and requiring both a limited effort of programming and a limited set of input data. However, the authors did not consider ripening of the plants.

An aspect which has not been considered much in this discussion about the necessity of dynamical models is that steady-state concentrations will not so often occur in the environment, due to the emission pattern of compounds. It is true that many persistent chemicals are ubiquitously distributed in the environment, and due to long-range transport in air and many years of relatively constant emissions, these compounds have approached phase equilibrium between soil and air in many areas of the world and rather constant concentrations in environmental compartments. If so, the steady-state assumption may be justified. However, concern is often about chemicals which are actively emitted in high amounts at a local scale. The emissions may be short pulses or (quasi-)constant emissions, often repeated, but normally not leading to a steady state. The concentrations of chemicals in soil due to these events are not 
constant, but increase and decline in a daily, weekly or annual rhythm. Steady-state models cannot be appropriate for such non-steady input function.

A variety of mechanistic model approaches has been developed in recent years, in order to predict contaminant uptake from soil or air into plants (e.g. [5-19]). In most cases, the underlying different equations have been solved for steady-state and/or numerically for dynamic studies. Numerical implementations allow a free input function, but may be difficult to handle in practice and may lack transparency (respective programs were usually set up in computer languages, such as Fortran or C). Moreover, numerical modelling is not very well suited for implementation into spreadsheets [20], which are common tools e.g. for risk assessment. Analytical solutions for the underlying differential equation systems of dynamic models would be highly desirable.

In this study, we compare different approaches of dynamic plant uptake modelling in order to identify relevant processes and time-scales of processes in the soil-plant-air system. In a novel approach, logistic plant growth is considered and transpiration is related to the change of plant mass. Based on the outcome, a new model concept for plant uptake modelling is developed, which applies an analytical matrix solution and allows the combination of steady-state, pulse and constant input. The analytical model is tested versus a numerical model implementation.

\section{Methods}

\subsection{Different types of input functions}

Figure 1 shows different types of input functions. E.g., pesticide application typically leads to a repeated pulse input as illustrated in Figure 1a where the compound is emitted at the beginning, after 30 and 60 time units at initial concentration $C_{0}$, decreasing exponentially with a first-order loss rate constant $k$ of 0.2 per time unit. The background level of the compound adds to observed concentrations in the plant. In Figure 1b, input from a (quasi-)constant external source changing at time $t=30$ units is considered, again applying a loss rate constant $k$ of 0.2 per time unit in the plant. In reality, however, often irregular input is given due to varying environmental conditions, as shown exemplarily in Figure 1c, where chemical input $I$ changes rapidly with time. The input 
function is important because the solution of linear differential equation (DE) systems depends on it, and only for some types of input, solutions have been found [21].

\subsection{Growth and transpiration of plants}

From agricultural production it is known that many annual crops, such as wheat, show a logistic growth curve [22-23]. This means, initial growth is exponential, but towards ripening, the growth slows down and finally stops. Accordingly, the change of plant mass $M(\mathrm{~kg})$ with time $t(\mathrm{~d})$ can be expressed as

$$
\frac{d M}{d t}=k \times M\left(1-\frac{M}{M_{\max }}\right)
$$

where $k\left(\mathrm{~d}^{-1}\right)$ is the rate constant for exponential growth and $M_{\max }(\mathrm{kg})$ is the maximum plant mass. Plant mass as a function of time can be calculated by integrating the growth function. With the initial plant mass $M_{0}$ follows

$$
M(t)=\frac{M_{\max }}{1+\left(\frac{M_{\max }}{M_{0}}-1\right) \times e^{-k t}}
$$

Transpiration $Q\left(\mathrm{~L} \mathrm{~d}^{-1}\right)$ of plants is closely related to growth via the transpiration coefficient $T_{C}$ $\left(\mathrm{L} \mathrm{kg}^{-1}\right)$ [24], and can be calculated as

$$
Q=T_{C} \times \frac{d M}{d t}=T_{C} \times k \times M\left(1-\frac{M}{M_{\max }}\right)
$$

where $Q$ is the water flux through the roots and out of the stem, related via $T_{C}$ to the change of total plant mass. Typical values of the transpiration coefficient $T_{C}$ for crop plants in humid areas range from 200 to 900 (default 500) L transpired water per kg produced biomass (dry weight) 
[24]. Considering e.g. trees or annual seed crops, water flux into leaves and fruits, $Q_{L}$ and $Q_{F}$, can be calculated from total (xylem) flow $Q$ by averaging with the respective (green) surface areas, where phloem flux adds for fruits [9] and subtracts for leaves:

$$
\begin{aligned}
Q_{L} & =Q \times \frac{A_{L}}{A_{L}+A_{F}}-\frac{d M_{F}}{d t} \times T_{C, P h} \\
Q_{F} & =Q \times \frac{A_{F}}{A_{L}+A_{F}}+\frac{d M_{F}}{d t} \times T_{C, P h}
\end{aligned}
$$

where $A_{L}$ and $A_{F}\left(\mathrm{~m}^{2}\right)$ are the surface areas of leaves and fruits (obtained by multiplying leaf and fruit mass $M_{L}$ and $M_{F}(\mathrm{~kg})$ with specific leaf and fruit area $S L A$ and $S F A\left(\mathrm{~m}^{2} \mathrm{~kg}^{-1}\right)$, respectively), $\mathrm{d} M_{F} / \mathrm{d} t\left(\mathrm{~kg} \mathrm{~d}^{-1}\right)$ is the change of fruit dry mass and $T_{C, P h}\left(\mathrm{~L} \mathrm{~kg}^{-1}\right)$ is phloem flux per fruit dry mass (10 $\mathrm{L} \mathrm{kg}^{-1}$ was assumed for $T_{C, P h}$, according to [9]). The phloem flux flows from leaves via stem to fruits. Under the assumption of phase equilibrium to xylem flux $[9,25]$, the mass flow can be subtracted from the flow to leaves and added to the flow to fruits.

As an illustrative example, Figure 2 shows simulated growth and transpiration of spring wheat with data related to $1 \mathrm{~m}^{2}$ (details on the parameterisation see Appendix 1). The initial mass is $5 \mathrm{x}$ $10^{-3} \mathrm{~kg}$ ( $5 \mathrm{~g}$ for seeds), and growth is exponential for time $t<70 \mathrm{~d}$, with growth rates specific to the different plant parts (Appendix 1). The growth of total plant mass is maximal at $t=90 \mathrm{~d}$, where also the induced Gaussian-like curve for transpiration $Q$ (in roots and stem) shows its peak. Water fluxes to leaves and fruits (corn) differ due to specific growth characteristics and processes, as explained above. For $t>135 \mathrm{~d}$, growth almost stops (final mass of $1.3 \mathrm{~kg}$ dry weight). Translated to reality, this is the phase, in which the fruit (corn) ripe, while leaves decay and the plant dries out. The optimum harvest time depends on the ripening of the corn. It has to be noted that the modelled growth curves are idealised, as real-life growth depends very much on weather, and growth rates are not constant. Storms, grazing or parasite calamities may also lead to a loss of biomass, i.e. to negative growth. 


\subsection{Model processes}

The models used for this study correspond to the latest version (March 2010) of the model series based on the PlantX approach [6-9]. Here we consider uptake from soil and air into plants and include the compartments soil, roots, stem, leaves and fruits. The following processes may be considered:

- continuous and/or pulse input into any compartment

- degradation, ageing, leaching, run-off and plant uptake, resulting in loss from soil

- uptake into roots with the transpiration water

- optionally: diffusion into roots

- growth dilution, degradation and metabolism in roots, stem, leaves and fruits

- translocation from roots to the stem, and from the stem to leaves and fruits with the transpiration stream

- loss from leaves and gain for fruits by phloem flux

- loss from stem, leaves and fruits to air

- gaseous and particle deposition from air to soil, stem, leaves, fruits

- optionally: transport to root, stem, leaves and fruits with attached soil

\subsection{Mass balance equations and numerical studies}

The mass balance equations used for the different plant compartments are mainly based upon the Fruit Tree model (FTM) [9] and are shown in Table 1. Different to the FTM, the DE were solved for the transient case. This allows to vary plant input data, such as plant mass, transpiration, surface area and permeability of the different plant compartments. Logistic mass growth and transpiration were treated according to Section 2.2. Details on the calculation of permeabilities are given in Appendix 2. As a further difference to the FTM, the change of compound mass in stem was considered in a different way (Equation 7, Table 1). In the FTM it is assumed that fine roots (root hairs and tips) are in phase equilibrium to the surrounding soil. From these fine roots, the chemical flows advectively to the main roots ("thick roots"). Mathematically, this can be 
treated as advection from soil to thick root, because in equilibrium, the concentration of the chemical in the transpiration water is the same as in the soil pore water. Direct diffusion into the main root was neglected, due to the small surface-to-area ratio of tree roots, but also because diffusive root uptake is difficult to parameterise. For smaller roots, this ratio is higher, and one of the questions to be addressed here was whether and how diffusive uptake from soil into roots changes the result. Simulations with diffusive uptake (Equation 6b, Table 1) were done for carrots, assuming cone geometry (Appendix 3). The following scenarios were compared: root uptake due to (i) advection only (Equation 6a, Table 1), (ii) diffusion only (Equation 6b), and (iii) advection plus diffusion (Equations 6a plus 6b).

Numerical modelling was carried out with Fortran 95, applying an Euler one-step solution scheme [21] to solve the differential equations given in Table 1. Plant concentrations $C(t)$ in each compartment were obtained by dividing compound mass $m(t)$ by compartment mass $M(t)$.

\subsection{Analytical solutions}

In the following, analytical solutions for compound concentrations are described. If plant growth is exponential, and for constant conditions (constant ratios transpiration to mass and surface area to mass), a first-order rate constant can be used for growth dilution [7-9, 21]. For advective uptake into main roots, the change of concentration is accordingly found by dividing Equation 6a by the root mass $M_{R}(\mathrm{~kg})$ and introducing a first-order growth rate constant $k_{R}\left(\mathrm{~d}^{-1}\right)$ [8-9]:

$$
\frac{d C_{R}}{d t}=\frac{Q}{M_{R}} \times K_{W S} \times C_{S}-\frac{Q}{M_{R} \times K_{R W}} \times C_{R}-\left(k_{R}+k_{R, \mathrm{deg}}\right) \times C_{R}
$$

Concentrations in the other plant compartments were derived from Equation 7 to 9 analogously. The resulting ordinary linear differential equations are of the general form

$$
\frac{d C}{d t}=-k C+b
$$


where $C$ is concentration $\left(\mathrm{mg} \mathrm{kg}^{-1}\right), k$ is a first-order loss rate constant $\left(\mathrm{d}^{-1}\right)$, i.e. the sum of all loss terms, and $b$ is total constant input $\left(\mathrm{mg} \mathrm{kg}^{-1} \mathrm{~d}^{-1}\right)$. Integration of Equation (11), with initial concentration $C(0)$ and for constant $k$ and $b$, yields the analytical solution

$$
C(t)=C(0) \times e^{-k t}+\frac{b}{k}\left(1-e^{-k t}\right)
$$

In all linear systems, steady-state is approached for $t \rightarrow \infty$. However, logistic growth brings a non-linear term into the equations, and steady-state of the linear DE (with constant data) might differ from the outcome of the non-linear dynamic simulation. Thus, steady-state concentrations were compared to the dynamic simulation for (i) exponential growth, and (ii) non-growth conditions, the latter by setting the growth rate constant to zero. The steady-state solution is obtained by setting the differential in Equation (11) to zero:

$$
C(t \rightarrow \infty)=\frac{b}{k}
$$

For roots (Equation 10), $b$ is $Q \times K_{W S} \times C_{S} / M_{R}$ and $k$ is $Q /\left(K_{R W} \times M_{R}\right)+k_{R}+k_{R, \text { deg }}$ (from Equation 6a). For the other compartments, $\mathrm{b}$ and $\mathrm{k}$ were derived accordingly. If more compartments are linearly related, this leads to a matrix of the general form

$$
\frac{d \vec{C}}{d t}=A \vec{C}+\vec{b}
$$

The equation system stemming from the mass balance equations for soil, root, stem and leaf or fruit (Table 1) can be transformed into a $4 \times 4$ diagonal matrix, if diffusion from root to soil (Equation $6 \mathrm{~b}$ ) is excluded: 


$$
\frac{d \vec{C}}{d t}=\left\{\begin{array}{cccc}
-k_{1} & 0 & 0 & 0 \\
k_{12} & -k_{2} & 0 & 0 \\
0 & k_{23} & -k_{3} & 0 \\
0 & 0 & k_{34} & -k_{4}
\end{array}\right\} \vec{C}+\vec{b}
$$

where $\vec{C}$ is the vector of concentration $\left(\mathrm{mg} \mathrm{kg}^{-1}\right), \vec{b}$ is the vector of constant input $\left(\mathrm{mg} \mathrm{kg}^{-1} \mathrm{~d}^{-1}\right)$, $k_{i j}$ are rate constants for the transfer from compartment $i$ to $j\left(\mathrm{~d}^{-1}\right)$ and $k_{i}$ are loss rate constants $\left(\mathrm{d}^{-}\right.$ ${ }^{1}$ ), i.e. the sum of all first-order loss processes in compartment $i$. In this matrix, compartment 1 is soil, 2 is roots, 3 is stem and 4 is leaves or fruits. A diagonal matrix implies unidirectional transfer from the lower to the higher compartment [21], i.e. from soil to roots, from roots to stem, and from stem to leaves and fruits. The matrix elements $k$ and $b$, derived from the differential equations for soil and for the plant compartments, are shown in Appendix 4. Such diagonal matrices can be solved analytically, depending on the initial conditions and the input function [21]. The steady-state solution of the matrix follows the general scheme (with compartment number $n)[10]$

$$
C_{n}(t \rightarrow \infty)=\frac{b_{n}}{k_{n}}+\frac{k_{n-1, n}}{k_{n}} \times C_{n-1}(t \rightarrow \infty)
$$

Dynamic analytical solutions for the differential equations above (Equation 17) for pulse input(s) are the same as for initial concentration $C_{n}(0) \neq 0[10]$. The analytical solution with constant input $b$ and initial condition $C_{n}(0) \neq 0$ is:

$$
\begin{gathered}
C_{1}(t)=\frac{b_{1}}{k_{1}}\left(1-e^{-k_{1} t}\right)+C_{1}(0) e^{-k_{1} t} \\
C_{2}(t)=A \times\left(e^{-k_{1} t}-e^{-k_{2} t}\right)+B \times\left(1-e^{-k_{2} t}\right)+C_{2}(0) e^{-k_{2} t} \\
C_{3}(t)=D \times\left(e^{-k_{1} t}-e^{-k_{3} t}\right)+E \times\left(e^{-k_{2} t}-e^{-k_{3} t}\right)+F \times\left(1-e^{-k_{3} t}\right)+C_{3}(0) e^{-k_{3} t}
\end{gathered}
$$




$$
C_{4}(t)=G \times\left(e^{-k_{1} t}-e^{-k_{4} t}\right)+H \times\left(e^{-k_{2} t}-e^{-k_{4} t}\right)+I \times\left(e^{-k_{3} t}-e^{-k_{4} t}\right)+J \times\left(1-e^{-k_{4} t}\right)+C_{4}(0) e^{-k_{4} t}
$$

where

$$
\begin{array}{ll}
A=\frac{C_{1}(0) k_{12} k_{1}-k_{12} b_{1}}{\left(k_{2}-k_{1}\right) k_{1}} & B=\frac{k_{12} b_{1}+k_{1} b_{2}}{k_{1} k_{2}} \\
D=A \frac{k_{23}}{k_{3}-k_{1}} & E=\frac{k_{23}\left(C_{2}(0)-A-B\right)}{k_{3}-k_{2}} \\
F=\frac{k_{23} B+b_{3}}{k_{3}} & \left.G=D \frac{k_{34}}{k_{4}-k_{1}}\right) \\
H=E \frac{k_{34}}{k_{4}-k_{2}} & \left.I=\frac{k_{34}\left(C_{3}(0)-D-E-F\right)}{k_{4}-k_{3}}\right)
\end{array}
$$

$J=\frac{k_{34} F+b_{4}}{k_{4}}$

The general solution with initial concentrations $C_{n}(0) \neq 0$ and constant input terms $b_{n}$, for $n \geq 2$ and $t_{0}=0$ follows the scheme:

$$
\begin{aligned}
C_{n}(t)= & \sum_{a=1}^{n-1}\left\{\prod_{i=a}^{n-1} k_{i, i+1} \cdot\left[C_{a}(0) \cdot \sum_{j=a}^{n} \frac{e^{-k_{j} t}}{\prod_{\substack{k=a, k \neq j}}^{n}\left(k_{k}-k_{j}\right)}+b_{a} \cdot \frac{1-e^{-k_{n} t}}{\prod_{l=a}^{n} k_{l}}-b_{a} \cdot \sum_{m=a}^{n-1}\left(\sum_{j=a}^{n} \frac{e^{-k_{j} t}}{\prod_{s=i}^{m} k_{s} \prod_{\substack{k=a, k \neq j}}^{n}\left(k_{k}-k_{j}\right)}\right)\right]\right\} \\
& +C_{n}(0) \cdot e^{-k_{n} t}+\frac{b_{n}}{k_{n}}\left(1-e^{-k_{n} t}\right)
\end{aligned}
$$

Even though complex, this solution allows the direct calculation of concentrations in all compartments at any time $t$ and for pulse- and/or constant input. 


\subsection{Model Implementation}

For repeated emissions and for non-constant input, superposition of $n$ periods was used to calculate the resulting concentrations. For this purpose, the simulation is split up into several periods. The concentration vector $\vec{C}(t)$ at the end of a specific period serves as initial concentration vector $\vec{C}(0)$ for the next period. Concentrations are additive, so that concentrations resulting from constant background contamination (e.g. from air) add to those concentrations from pulse input and constant input. Time-varying input can be simulated by "rectangular" input functions, i.e. by splitting the simulation up into several periods with different constant input. During each period, the conditions and parameters need to be constant, but they may differ from one period to the other. This allows the simulation of seasonal changes, day/night cycles, logistic growth or other non-constant conditions.

The resulting Multi-Cascade model was set up for annual seed crops (Figure 3). Leaves and fruits (i.e., corn) were set up as parallel compartments. Matrix elements can be defined differently for each period. To consider growth, plant mass (for root, stem, leaf and fruits) was calculated with Equation (2) as an average for each period, for the middle of the period. Growth dilution was approximated by first-order growth rate constants $k_{\text {growth,ip }}$ for each plant compartment $i$ in every period $p$ :

$$
k_{\text {growth }, i, p}=\ln \left(\frac{M_{i, p}}{M_{i, p-1}}\right) / \Delta t_{p}
$$

where $M_{i, p}$ and $M_{i, p-l}(\mathrm{~kg})$ are the mass of plant compartment $i$ in period $p$ and $p$-1, respectively, and $\Delta t_{p}$ is the period length (d). The Multi-Cascade model was realized as Microsoft Excel ${ }^{\mathrm{TM}}$ spreadsheet.

\section{Results}

Simulations were carried out for contaminant uptake into carrots and spring wheat. Aims were to elucidate the influence of plant growth and to investigate, under which conditions logistic growth 
can be replaced by linear approximation. Another question addressed was on diffusive uptake into roots and whether and when this can be omitted, as this process requires a number of highly uncertain parameters and small time steps to be solved numerically, and furthermore hampers an analytical matrix solution by backward flow (a non-diagonal matrix element). Simulations were also done in order to test the Multi-Cascade model against the numerical solution of the underlying differential equations for plant uptake, in order to verify the correct implementation of both approaches.

Input data for the modelling studies are summarised in Tables 2 to 4 . These data were used both for dynamic calculations (numerical and Multi-Cascade model) and steady-state investigations. Soil input data (Table 2) refer to a Danish reference soil. Size-independent plant data (Table 3) were mostly taken from the carrot model [8] and the leafy vegetables model [7]. Size-dependent and growth-related parameters (Table 4) were derived for carrots and wheat, as described in detail in Appendices 1 and 3. Trichloroethene (TCE) was used as test compound for illustrative purposes (Table 2), the scenario does not represent a real event. Although TCE is a common pollutant in groundwater but rarely expected in upper soil (unless e.g. via irrigation water) it was selected as a problematic test compound for modelling, posing a particular challenge due to stiff matrices (high exchange rates between leaves and air, comparatively slow uptake from soil). Pesticide uptake was investigated in detail in another study, applying the Multi-Cascade model in a version with pulse input [26].

\subsection{Dynamic uptake into carrots}

Figure 4 shows results of the dynamic simulation of trichloroethylene (TCE) uptake from soil (constant concentration of $1 \mathrm{mg} \mathrm{kg}^{-1}$ ) into carrot. For the simulations, advective uptake only, diffusive uptake only and both processes together were modelled as three different cases (cf. Section 2.4). Logistic growth was considered, details on carrot mass and geometry (volume, area, length, radius) and transpiration as a function of time are given in Appendix 3. As can be seen from Figure 4a, all three approaches yield very similar results for the calculated mass of TCE in roots. Contaminant mass taken up by advection only is slightly less than by diffusion only (Figure 4a), as transpiration is coupled to the growth of plant mass (Equation 3) and slows down 
at day 70 (Figure 3.1b, Appendix 3). The calculated TCE concentrations are slightly different (Figure $4 \mathrm{~b}$ ). Advective uptake plus diffusion gives the same initial concentration maximum as diffusive uptake only. Advection only is slower and leads to slightly lower, but constant concentration. The differences in the shape of the concentration curves can be explained by a different influence of growth on the considered processes and respective dilution effects. After the initial maximum is reached, concentration by diffusive uptake only is decreasing, which is due to (i) an increasing diffusion length (carrot radius) with time and (ii) a slower growth of carrot area (effective for diffusion) compared to carrot mass (cf. Figure 3.1, Appendix 3). This decrease stops when mass growth slows down, so that the concentration curve for diffusive uptake shows a minimum at about day 70 (Figure 4b). Overall, the differences between the approaches (with/out diffusion) are small, and perhaps not relevant in practice.

A sensitivity study was performed for $\log K_{O W}$-values from -2 to 9 (very polar to very lipophilic) and for varying $K_{A W}\left(1\right.$ to $\left.10^{-9} \mathrm{~L} \mathrm{~L}^{-1}\right)$. The molar mass was set to $300 \mathrm{~g} \mathrm{~mol}^{-1}$, the degradation rate $k_{d e g}$ and concentration in air $C_{\mathrm{A}}$ to zero. Steady-state was calculated for (i) exponential growth and advective uptake and (ii) for non-growth conditions (Section 2.5), using root mass $M_{R}$ and transpiration $Q$ at time $t=30 \mathrm{~d}$ as input data. Three variants of the dynamic simulation (with advection, with diffusion, with both) calculated for harvest time (day 150) were compared to the steady-state.

Figure $4 \mathrm{c}$ shows carrot concentrations as a function of $\log K_{O W}$, for $K_{A W}=1 \mathrm{~L} \mathrm{~L}^{-1}$ (low sensitivity of $K_{A W}$, as well as of molar mass, as similarly observed with Fruit Tree model simulations [9]). The dynamic simulations with advection only, and with advection plus diffusion, do not differ over the whole range of $\log K_{O W}$. Diffusion alone leads to lower root concentrations at high $\log$ $K_{O W}$. Steady-state calculations with exponential growth dilution, $\mathrm{C}(\infty)$ exp-gr, are close to the result of the dynamic simulation with advection. Without growth dilution, $C(\infty)$ non-gr, concentrations are overpredicted for lipophilic compounds. In conclusion, the concentration of chemicals in root vegetables at harvest is sufficiently described by a steady-state model with exponential growth, as described in [8]. 


\subsection{Dynamic uptake into spring wheat}

Figure 5 shows results of simulated uptake of TCE into spring wheat. Dynamic concentrations were calculated numerically as described in Section 2.4, considering logistic plant growth (details see Appendix 1). A constant soil concentration of $1 \mathrm{mg} / \mathrm{kg}$ was assumed, and air concentration as well as degradation rate constants (in all compartments) were set to zero. Advective uptake only was considered for the roots (Equation 6a). After increasing rapidly at the beginning, root concentrations are nearly constant, whereas stem concentrations decrease after about day 90 towards the end of the vegetation period (Figure 5a). This decrease can be explained by continuing diffusive loss to the atmosphere and a decreasing compound flux from roots to stem when transpiration goes down at ripening (cf. Figure 2).

Leaf and corn concentrations (Figure 5b) increase to a first plateau-like maximum, then a peak is reached around day 75, resulting from the water flow maxima to leaves and corn (cf. Figure 2 and Figure 1.1, Appendix 1). Towards ripening, when water flow goes down, concentrations decrease rapidly, again due to loss to air. In addition to the dynamic results, steady-state concentrations are shown in Figure 5, referring to the exponential growth phase (in analogy to above, growth-related plant parameters were determined for $t=30 \mathrm{~d}$ ). Steady-state concentrations correspond well to dynamic results for the roots, but for the stem there is a slight overestimation towards ripening (Figure 5a). For leaves and fruits, the steady-state assumptions yield good results for the exponential growth phase (up to day 30), however underestimate "real concentrations" later (around the peak at day 75) und highly overestimate concentrations at harvest time.

Again, a sensitivity study was carried out for contaminant uptake into spring wheat as a function of different $\log K_{O W}(-2$ to 9$)$ and $K_{A W}\left(1\right.$ to $\left.10^{-9} \mathrm{~L} \mathrm{~L}^{-1}\right)$. The molar mass was set to $300 \mathrm{~g} \mathrm{~mol}^{-1}$, the degradation rate $k_{d e g}$ and concentration in air $C_{\mathrm{A}}$ to zero. Figure 6 shows the result of the dynamic simulation at $t=30 \mathrm{~d}$ (exponential growth phase) and at $t=150 \mathrm{~d}$ (harvest, after ripening). It also shows the outcome of the steady-state simulation with exponential growth, $C_{\text {exp }}(\infty)$, and with (nearly zero) growth at the ripening phase, $C_{r i p}(\infty)$. For $C_{r i p}(\infty)$, growth related 
parameters were determined for $t=150 \mathrm{~d}$, and growth rate constants $k$ approximated with Equation 19 for the last ten days, i.e. day 140 to 150 (very low values).

Generally, the calculated concentrations are highest for low $\log K_{\mathrm{OW}}$, and they increase with decreasing $K_{\mathrm{AW}}$. This was postulated before [9]. The difference of calculated concentrations at $t$ $=30 \mathrm{~d}$ and $150 \mathrm{~d}$ is small for roots and stem, and also for fruits (and leaves, not shown), when $K_{\mathrm{AW}}$ is low. Volatile compounds $\left(K_{\mathrm{AW}} \geq 10^{-3}\right)$ show lower concentrations in fruits (and leaves, not shown) at harvest, because the transport from soil stops when the fruits ripe (Figure 2), while loss to air continues. Concentrations in roots and stem are adequately predicted by the steadystate calculation relating to exponential growth, $C_{\exp }(\infty)$, which is also always very close to the dynamic concentration at $t=30 \mathrm{~d}$. For $t=150 \mathrm{~d}$, the low-growth (nearly non-growth) steadystate calculation, $C_{r i p}(\infty)$, is often closer, in particular for polar compounds ( $\left.\log K_{\mathrm{OW}} \leq 2\right)$, but not for lipophilic compounds.

A more detailed sensitivity study was done recently [26], where a Monte-Carlo analysis was carried out varying all input parameters at the same time by $10 \%$ of the mean value (i.e., variation with a standard deviation of 0.1 times the default, using a normal distribution). In order to predict the peak and final concentration of an insecticide in fruits, a high sensitivity was found for degradation rates or for temperature (because temperature affects degradation rates). The influence of other plant-related and environmental parameters was comparatively low.

Steady-state simulations are the method of choice for chemical risk assessment: there, the effect of continuous, infinite emissions has to be evaluated. Models for this purpose are therefore typically steady-state [34]. The steady-state solution with growth dilution is identical to the plant uptake model currently implemented in the EU chemical safety assessment tool, EUSES [27]. As can be seen from Figure 6, this model (represented by the steady-state concentrations) is either close to the more complex dynamic model, or it overestimates concentrations at harvest. It can thus be considered as "conservative in some cases".

\subsection{Multi-Cascade model vs. numerical solution}

Figure 7 shows simulated uptake of TCE into crops, obtained from numerical modelling in comparison to application of the analytical Multi-Cascade model. The same scenario as in 
Section 3.2 is considered (Tables 2 to 4 ). Three different period lengths $\Delta t_{p}$ were chosen for calculations with the Multi-Cascade model, with $\Delta t_{p}=30 \mathrm{~d}$ (five periods), $5 \mathrm{~d}$ (30 periods) and 1 $\mathrm{d}$ (150 periods). The Multi-Cascade simulations represent the results of the numerical simulation well (less than 10-30\% difference). Finer time intervals approximate the numerical results of course better, so that for $\Delta t_{p} 1$ and $5 \mathrm{~d}$, in average, practically the same results are obtained as for the numerical solution. Multi-Cascade results for period length $\Delta t_{p}=30$ are too rough. The steplike structure of the Multi-Cascade model curves for TCE (Figure 7a to c) is due to the applied superposition principle and reflects the length of the chosen periods. This behaviour is visible for stem, leaves and corn (more pronounced for leaves and corn) and can be explained by rapid adjustments of concentrations between the periods, due to high exchange rates. The model does not show this behaviour for compounds with slower rates.

\section{Discussion}

\subsection{Analytical versus numerical models}

Results of a model intercomparison indicated that dynamic uptake models offer performance advantages for acute exposure durations and for rapidly changing environmental media [4]. Many dynamic plant uptake models use numerical iterations to solve the underlying differential equations $[5-6,11,18,35]$. The iteration may require rather small time steps, in order to avoid numerical errors and to meet stiff matrices (e.g. due to slow processes in soil and fast exchange between leaves and air). Numerical models are often implemented in FORTRAN or C. Models applying analytical solutions can be used in spreadsheet format and have the advantage of being stable, easy to learn and to distribute (open source code, avoidance of incompatibility problems). Several analytical dynamic plant uptake models exist e.g. for the aerial plant part [7] and for root uptake and translocation to stem and fruits [12, 16-17], but these are limited to constant conditions (i.e. one period). Our new approach is based on a diagonal matrix, which is solved analytically. By applying the superposition principle, $n$ different periods can be considered, thus allowing to approximate also non-linear scenarios and repeated emissions. 


\subsection{Downward phloem transport and diffusive exchange between soil and roots}

An obstacle towards analytical models for the complete soil-air-plant is the lack or the complexicity of suitable mathematical solutions. Generally, solutions always exist for linear (i.e. first-order) DE systems, though only for a few input types. Analytical solutions are in particular "easy" for diagonal matrices. But a diagonal matrix implies unidirectional transfer between the compartments, i.e. backflow is excluded (cf. Section 2.5). A diagonal matrix of the system is thus only achieved when (i) downward transport in phloem (from leaves to stem and further to roots) and (ii) diffusive exchange between soil and roots can be omitted.

Phloem transport downwards (in the opposite direction to the xylem) is relevant for weak acids, due to the ion trap effect, but other compounds do not accumulate in phloem [25]. Very polar neutral compounds may also be transported in the opposite direction of the xylem because they leave the phloem sieve tubes very slowly [36]. For the less polar neutral compounds, xylem and phloem concentrations will equilibrate within a short distance $[25,35]$. If so, the transport of chemical in the phloem gets irrelevant (at least when the emission source is soil), because the water flux in phloem is only a few percent of that in xylem.

Diffusion into roots does not deserve consideration (i) if the roots come close to equilibrium, which is the case for all polar and medium lipophilic compounds $\left(\log K_{O W}<3\right)$ and (ii) if the same result (negligible differences) is obtained without diffusion. The major difference in simulation with and without consideration of diffusion is the time period required to approach the result (typically only a few days or less, see above), as diffusion is faster compared to advection [35]. But if the concentration at harvest is considered, the time span is long enough that the consequences of omitting diffusion into roots from the equation are negligible.

\subsection{Treatment of plant growth}

From the simulation results it can be seen that exponential growth instead of logistic growth may be applied when the harvest is during the exponential phase of growth, as it is for many root vegetables, most green vegetables (lettuce etc.), green fodder and grassland. The profit-oriented farmer will harvest his crops at the earliest possible date and before productivity falls. E.g., 
meadows are cut after two to three months, to avoid loss of productivity and a lower quality of produce. Lettuce must be harvested before ripening, as otherwise bitter alkaloids will form [37]. There are two occasions where growth can be totally neglected. First, for polar compounds and uptake into roots $\left(\log K_{\mathrm{OW}} \leq 2\right)$ and stem $\left(\log K_{\mathrm{OW}} \leq 1\right)$; second, for leaves and corn (or fruits) in the ripening phase (when growth is zero), and simultaneously high exchange or decay rates $\left(K_{A W}\right.$ $10^{-3}$ or higher and $\log K_{\mathrm{OW}}<2$ ). Then, the result approaches quickly steady-state. Note that then also transpiration is zero, because it is coupled to growth. If logistic growth cannot be omitted, it can be simulated by step-wise linear (i.e. exponential) approximation, as applied in the MultiCascade model.

\subsection{Steady-state versus dynamic modelling}

Results shown above indicate that steady-state assumptions yield reasonable values for the exponential growth phase (slight overestimations for very lipophilic compounds possible, see above), given that input is constant. Similarly, dynamic results obtained with a fugacity based plant bioaccumulation model approached steady-state closely for exponential growth and a wide range of hypothetical compounds in the chemical partitioning space [5]. There, growth dilution shortened the time needed to approach steady state in the leaf compartment for chemicals with high $K_{O A}$ (octanol-air partition coefficient) to about 30 days (4 doubling times). The authors concluded that it is theoretically possible for all chemicals to approach steady-state within the lifetime of a fast growing plant, if the exposure and the relevant environmental parameters are constant [5]. However, it was also found that if the plant does not grow, steady-state solutions will not succeed. We did two steady-state simulations, one with exponential growth (parameters adjusted to the exponential growth phase) and one with very low, i.e. nearly zero growth (parameters adjusted to the ripening phase). The latter fits better for concentrations at harvest (in the ripening phase in which plant growth is stopping) for polar and volatile compounds (Figure 6). Dynamic modelling is also needed if input is non-constant. 


\subsection{Applicability and limitations of the new concept}

The Multi-Cascade model is limited to neutral organic compounds, like all models based on the PlantX concept. The presented approach considers uptake from air and soil, and pulse input as well as constant input to soil and eventually into plant compartments. If input is directly on leaves or fruits (pesticide spray application), other (less complex) models may be preferable. Separate periods can be simulated, with parameters and input being variable from period to period. Implemented into a spreadsheet, the resolution (number and length of periods) can be chosen quite freely. If the resolution is chosen fine enough, depending on the exchange and elimination rates, practically no difference will be seen compared to the numerical solution. The Multi-Cascade approach, in a version with pulse input and modified to consider temperature dependency, was applied to model drip irrigation of an insecticide [26]. The agreement between measured and simulated concentrations was high, and complete agreement could be achieved by the fit of few input parameters. This underlines that the overall model structure describes the system adequately, reflecting the general uptake characteristics (concentration increase and decline as well as peaks). It has to be kept in mind that an important purpose of mechanistic mathematical modelling is to gain insight into processes in the complex soil-air-plant system, to identify their relevance and key parameters, which may be investigated in further (experimental) studies.

\section{Conclusions}

Dynamic modelling is required for the simulation of scenarios with non-constant input. In case of constant input, steady-state calculations yielded reasonable results if plant growth was exponential. Plant growth is quasi-exponential in the initial growth phase, but slows down when the plants ripen. If harvest is in or after ripening, dynamic modelling may be preferable, except for some chemical properties. Growth assumptions may be simplified in the exponential growth phase (using exponential growth) and in the ripening phase (omitting growth for leaf and fruits and chemicals with a high exchange rate, $\mathrm{K}_{\mathrm{AW}} \geq 10^{-3} \mathrm{~L} \mathrm{~L} \mathrm{~L}^{-1}, \log \mathrm{K}_{\mathrm{OW}}<2$ ), otherwise the 
consideration of logistic growth is necessary. The new Multi-Cascade model uses an analytical solution of the ordinary differential equation system for several types of input function, which can be combined. The combination of solutions allows to mimic most input functions that are relevant in practice, and also to approximate periodic cycles, such as day/night and annual variations. Step-wise linear (exponential) approximation of logistic growth, with average values for growth related parameters and adjusted first-order growth rate constants specific to defined periods, revealed to be an appropriate technique. If preferred, the underlying differential equation system can also be solved numerically, but this prohibits an implementation as pure spread-sheet solution.

The results of this study highlight the potential of the Multi-Cascade modelling approach for predicting chemical fate in the soil-plant-air-system when the input pattern is dynamic. The Multi-Cascade model was designed for repeated pulse input (e.g. application of pesticides, application of manure to soil) and repeated constant input over defined periods (e.g. irrigation or deposition from air). The model is available for free.

\section{Acknowledgements}

This work was partly funded by the European Union (European Commission, FP7 Contract No. 213161, project ModelPROBE).

\section{Model Availability}

The Multi-Cascade model and other plant models, with manuals, are freely available online (http:/homepage.env.dtu.dk/stt/). 


\section{Appendix 1. Wheat growth}

Reported data on wheat plant mass is usually related to EC-growth stages, a 2-digit code encompassing characteristic growth phases [38]. For data on the dry mass of spring wheat [33], in the first step, the reported EC-stages were dated in order to obtain dry mass versus time. This was done using typical durations of growth phases for spring wheat in Germany (http://www.raiffeisen.com/pflanzen/ackermanager/ec_html). Obtained EC-stages as a function of time are shown in Figure 1.1a. Observations and model calculations on growth dynamics of winter wheat [39] indicate similar tendencies. Despite the difference between spring wheat and winter wheat development, such as a longer duration of early development stages for winter wheat, the succession of EC-stages show similar general characteristics. Thus, the reported ECstages for spring wheat [33] were dated following the curve characteristics described above for winter wheat, shown as cross symbols (best estimates) in Figure 1.1a.

In the next step, logistic growth curves were fitted to the data set derived above, i.e. shoot (straw) plus corn dry mass versus time (individual curves for shoot and corn). This was done by inverse modelling (Equation 2, Microsoft Excel TM spreadsheet calculations with manual least square fit). Required parameters were initial mass $M_{0}$, maximum mass $M_{\max }$ and exponential growth rate constant $k$ (Section 2.2). Concerning $M_{0}$, an initial plant dry mass of $5 \mathrm{~g}$ per $\mathrm{m}^{2}$ field was considered as a typical value, taking into account (i) seed amounts of 300 to 450 seeds per $\mathrm{m}^{2}$ field for spring wheat, (ii) a thousand-seed (wet) weight of $45 \mathrm{~g}$, (iii) a seed dry matter content of $86 \%$, and (iv) germination of $1 / 2$ to $1 / 3$ of the seeds (data according to [33]). All masses in the following are related to dry weight $(\mathrm{dw})$, and to $1 \mathrm{~m}^{2}$ field. Assuming that the initial ratio root to shoot dry mass is $1: 1[31,33]$, an initial mass $M_{0}$ of $0.0025 \mathrm{~kg}$ was considered for the shoot (all masses refer to $1 \mathrm{~m}^{2}$ field). Concerning $M_{\max }, 0.50$ and $0.56 \mathrm{~kg}$ were considered for shoot and corn, respectively [33]. For the shoot, $k$ was adjusted to yield a logistic growth curve $\left(k_{\text {Shoot }}=\right.$ $0.075 \mathrm{~d}^{-1}$ ). For corn, $k$ and $M_{0}$ were adjusted, obtaining $k=0.14 \mathrm{~d}^{-1}$ and a negligibly low $M_{0}$ of $5.6 \times 10^{-6} \mathrm{~kg}$ (in reality, fruit development starts later in the vegetation period). Figure $1.1 \mathrm{~b}$ shows the modelled curve "shoot plus corn mass", where the fitted curves for shoot and corn mass are added, in comparison to the data set of measured dry weights with approximated date (see above). 
As no measured data were available for root mass as a function of time, similar growth characteristics as for shoot were assumed (same $k$ ), with $M_{0}=0.0025 \mathrm{~kg} \mathrm{dw}$ (initial ratio root to shoot of 1:1, see above) and a final root mass of $0.25 \mathrm{~kg} \mathrm{dw}$ or half the shoot mass [30].

In order to consider stem and leaf as separate compartments, specific growth curves were fitted in the next step. It was assumed that at early growth phases the ratio between stem and leaf dry mass is approximately $1: 1$, and at the ripening phase the dry mass of the leaves is only $1 / 10$ of the total dry mass of the above-ground plant [31, 40]. Curves for stem and leaf mass as a function of time were fitted by adjusting $k$ (with $M_{0}=0.00125 \mathrm{~kg}$ for stem and leaf; $M_{\max }=0.45$ and $0.05 \mathrm{~kg}$ for stem and leaf, respectively; mass stem plus mass leaf = mass shoot). As no measured data specifically for stem and leaf were available, $k$ was adjusted in order to meet general observations on growth $[38,41]$ such as early leaf growth, and rapid stem growth during the stem elongation stage (approx. between day 50 and 70). It was assumed, that growth phases of distinct plant parts overlap.

In order to model plant surface areas as a function of time, factors were determined that relate surface area to plant mass ("specific areas" in units of $\mathrm{m}^{2} \mathrm{~kg}^{-1}$, which are multiplied with respective mass). For wheat stems growing on $1 \mathrm{~m}^{2}$ field, a total (final) surface area of about 5 $\mathrm{m}^{2}$ is obtained when assuming a final stem radius of $3 \mathrm{~mm}$, a final stem height of $1 \mathrm{~m}$ and a total number of about 300 stems per square meter. Given a total final stem mass $0.45 \mathrm{~kg} \mathrm{dw}$ on $1 \mathrm{~m}^{2}$ field, this leads to a specific stem area (SStA) of about $10 \mathrm{~m}^{2} \mathrm{~kg}^{-1}(\mathrm{dw})$. For wheat leaf, a specific leaf area (SLA) of $30 \mathrm{~m}^{2} \mathrm{~kg}^{-1}(\mathrm{dw})$ is reported as a typical value [32]. Taking into account a seed diameter of $2 \mathrm{~mm}$ (spherical shape considered), and 20,000 seeds per $\mathrm{m}^{2}$ as a typical number [4243], a total (final) corn surface area of about $1 \mathrm{~m}^{2}$ is obtained. Given a final corn mass of $0.56 \mathrm{~kg}$ (dw) per $\mathrm{m}^{2}$, a specific corn area (SCA) of $2 \mathrm{~m}^{2} \mathrm{~kg}^{-1}(\mathrm{dw})$ can be assumed.

\section{Appendix 2. Calculation of permeabilities}

The permeability for diffusive exchange between soil and roots $P_{R}\left(\mathrm{~m} \mathrm{~d}^{-1}\right)$ was obtained as diffusion coefficient in root tissue divided by the diffusion pathway, i.e. root radius $r_{R}$ (details see [9]). 
For diffusive exchange between surface area and air, the cuticle pathway was considered for stem permeability $P_{S t}$, i.e. $P_{S t}=P_{C, t o t a l}$, where $P_{C, t o t a l}$ is the total permeability of the cuticle pathway. After the chemical has crossed the cuticle, it is assumed that next resistances are provided by the air boundary layer surrounding the roots and the aqueous layer within the root matrix. Thus, $P_{C \text {,total }}$ is given by

$$
P_{C, \text { total }}=\frac{1}{\left(1 / P_{C}\right)+\left(1 / g_{\text {Air }} \times K_{A W}\right)+\left(1 / P_{\text {Aqua }}\right)}
$$

where $P_{C}\left(\mathrm{~m} \mathrm{~d}^{-1}\right)$ is permeability of the cuticle (function of $\left.\log K_{O W}\right)$ and $g_{A i r}\left(\mathrm{~m} \mathrm{~d}^{-1}\right)$ is conductance of the air boundary layer (function of molar mass). Permeability of the aqueous layer $P_{\text {Aqua }}$ is $D_{W}\left(\mathrm{~m}^{2} \mathrm{~d}^{-1}\right)$ divided by $d_{x}(\mathrm{~m})$, where $D_{W}$ is diffusion the coefficient of the chemical in pure water (function of molar mass) and $d_{x}$ is the diffusion length (details on $P_{C}, g_{A i r}$ and $D_{W}$, see [9])

For leaves and fruits it is assumed that exchanges of the chemical occur through the cuticle and stomata in parallel [9], with leaf permeability $P_{L}=P_{S}$ (leaf) $+P_{C, t o t a l}$ and fruit permeability $P_{F}=$ $P_{S}($ fruit $)+P_{C \text {,total }}$. Stomata permeability $P_{S}\left(\mathrm{~m} \mathrm{~d}^{-1}\right)$ is a function of leaf transpiration $Q_{L}$ and leaf area $A_{L}$ for $P_{L}$ and fruit transpiration $Q_{F}$ and fruit area $A_{F}$ for $P_{F}$, so it is time dependent if transient conditions are considered. It is also a function of temperature, relative humidity, $K_{A W}$ and molar mass (details see [9]).

\section{Appendix 3. Geometry and growth of carrots}

Cone geometry was considered for carrots, with volume $V_{R}\left(\mathrm{~m}^{3}\right)$ and surface area $A_{R}\left(\mathrm{~m}^{2}\right)$, in contact with soil, being

$$
V_{R}=1 / 3 \pi \times r_{R}^{2} \times l_{R} \quad \text { (3.1) and } \quad A_{R}=\pi \times r_{R} \sqrt{r_{R}^{2}+l_{R}^{2}}
$$

where $r_{R}(\mathrm{~m})$ and $l_{R}(\mathrm{~m})$ are carrot radius and length. Volume $V_{R}$ is derived from mass $M_{R}(\mathrm{~kg})$ and density $\rho_{R}\left(\mathrm{~kg} / \mathrm{m}^{3}\right)$ as $V_{R}=M_{R} / \rho_{R}$. Logistic growth was considered for $M_{R}$, and a temporally 
constant relationship $x_{l / r}$ between carrot length $l_{R}$ and carrot radius $r_{R}$ was assumed as a simplified assumption, with $x_{l / r}=l_{R} / r_{R}$. Inserting $x_{l / r}$ into Equation (3.1), carrot length and radius are

$$
l_{R}(t)=\sqrt[3]{\frac{3 \times V_{R}(t)}{\pi \times\left(x_{l / r}\right)^{-2}}} \quad \text { (3.3) and } \quad r_{R}(t)=\sqrt[3]{\frac{3 \times V_{R}(t)}{\pi \times x_{l / r}}}
$$

The dynamics of simulated carrot growth and transpiration (calculated using Equation 2 and 3, Section 2.2) is illustrated in Figure 3.1, based on generic assumptions (initial mass $M_{0}$ and final mass $M_{\max }$ of 0.001 and $1 \mathrm{~kg}$ dry weight, respectively, for $1 \mathrm{~m}^{2}$ field containing 36 carrots; growth rate constant $k$ of $0.1 \mathrm{~d}^{-1}$; final radius of $0.015 \mathrm{~m}$ ). At harvest time, i.e. after 150 days, an individual carrot has a length of about $12 \mathrm{~cm}$, a radius of $1.5 \mathrm{~cm}$ and a mass of about $28 \mathrm{~g}$ (Figure 3.1a and $\mathrm{b}$ ). The ratios transpiration stream $Q$ to mass $M_{R}$ and surface area (in direct contact to soil) $A_{R}$ to $M_{R}$ are decreasing with time (Figure 3.1c). As carrot mass and volume increase by a factor of 1000 until harvest time and the ratio $l_{R}$ to $r_{R}$ is constant, $A_{R}$ increases by a factor of 100 and $l_{R}$ and $r_{R}$ increase by a factor of 10 (see equations above).

\section{Matrix elements considered in the Multi-Cascade model}

\begin{tabular}{lll}
\hline Compartment & $\begin{array}{l}\text { Loss rate constants } \boldsymbol{k}_{\boldsymbol{i}}\left(\mathbf{d}^{\mathbf{- 1}}\right) \text { and total constant input } \boldsymbol{b}_{\boldsymbol{i}} \\
(\mathbf{m g} / \mathbf{d})\end{array}$ & $\begin{array}{l}\text { Transfer rate } \\
\text { constants } \boldsymbol{k}_{\boldsymbol{i j}}\left(\mathbf{d}^{\mathbf{1}}\right)\end{array}$ \\
\hline$k_{1}=\frac{\left(Q_{\text {runoff }}+Q_{\text {leach }}+Q\right) K_{W S}}{M_{S}}+1000 \frac{A_{S} P_{S} \rho_{S, \text { wet }}}{M_{S}}+k_{S, \mathrm{deg}}$ & \\
$b_{1}=\left(\frac{A_{S} P_{S} \rho_{S, \text { wet }}\left(1-f_{P}\right)}{K_{A W} K_{W S} M_{S}}+\frac{A_{S} v_{\text {dep }} f_{P}}{M_{S}}\right) C_{A}+\frac{I_{\text {ext }, 1}}{M_{S}}$ & $k_{12}=\frac{Q \times K_{W S}}{M_{S}}$ \\
\hline Root & $k_{2}=\frac{Q}{M_{R} \times K_{R W}}+k_{R}+k_{R, \text { deg }}$ & \\
$b_{2}=\frac{I_{e x t, 2}}{M_{R}}$ &
\end{tabular}




\begin{tabular}{lll}
\hline Stem & $k_{3}=\frac{Q}{M_{S t} K_{S t W}}+1000 \frac{A_{S t} P_{S t}}{M_{S t} K_{S t W}}+k_{S t}+k_{S t, \mathrm{deg}}$ & $k_{23}=\frac{Q}{M_{S t} K_{R W}}$ \\
$b_{3}=\left(\frac{A_{S t} P_{S t}\left(1-f_{P}\right)}{K_{A W} M_{S t}}+\frac{A_{S t} v_{d e p} f_{P}}{M_{S t}}\right) C_{A}+\frac{I_{e x t, 3}}{M_{S t}}$ & $k_{34 a}=\frac{Q_{L}}{M_{L} K_{S t W}}$ \\
\hline Leaves & $k_{4 a}=1000 \frac{A_{L} P_{L}}{M_{L} K_{L W}}+k_{L}+k_{L, \mathrm{deg}}$ & \\
\hline Fruits & $b_{4 a}=\left(\frac{A_{L} P_{L}\left(1-f_{P}\right)}{K_{A W} M_{L}}+\frac{A_{L} v_{d e p} f_{P}}{M_{L}}\right) C_{A}+\frac{I_{e x t, 4 a}}{M_{L}}$ & $k_{34 b}=\frac{Q_{F}}{M_{F} K_{F W}}$ \\
$k_{4 b}$ & $=1000 \frac{A_{F} P_{F}}{M_{F} K_{F W}}+k_{F}+k_{F, \mathrm{deg}}$ & \\
$b_{4 b}$ & $=\left(\frac{A_{F} P_{F}\left(1-f_{P}\right)}{K_{A W} M_{F}}+\frac{A_{F} v_{d e p} f_{P}}{M_{F}}\right) C_{A}+\frac{I_{e x t, 4 b}}{M_{F}}$ & \\
\hline & &
\end{tabular}

Notes: $Q_{\text {runoff }}$ and $Q_{\text {leach }}$ are runoff and leaching rate, respectively $\left(\mathrm{L} \mathrm{d}^{-1}\right), M_{S}$ is soil mass $(\mathrm{kg}), A_{S}$ is surface area of soil $\left(\mathrm{m}^{2}\right), P_{S}$ is permeability of soil $\left(\mathrm{m} \mathrm{d}^{-1}\right), \rho_{S, \text { wet }}$ is wet density of soil $\left(\mathrm{kg} \mathrm{L}^{-1}\right)$, $k_{S, \text { deg }}$ is degradation rate constant in soil $\left(\mathrm{d}^{-1}\right) ; I_{e x t, I}$ is external constant input to compartment $i$ $\left(\mathrm{mg} \mathrm{d}^{-1}\right)$; other symbols according to Table 1; diffusive loss from soil (second term of $k_{l}$ ) and input to soil from air (first term of $b_{1}$ ): calculated according to [21]. 


\section{References}

[1] C.N. Legind, and S. Trapp, Modeling the exposure of children and adults via diet to chemicals in the environment with crop-specific models, Environ. Pollut. 157 (2009), pp. 778-785.

[2] J.L. Schnoor, L.A. Licht, S.C. McCutcheon, N.L. Wolfe, and L.H. Carreira, Phytoremediation of organic and nutrient contaminants, Environ. Sci. Technol. 29 (1995), pp. A318-A323.

[3] D.A. Kleier, and F.C. Hsu, Phloem mobility of xenobiotics .7. The design of phloem systemic pesticides, Weed Sci. 44 (1996), pp. 749-756.

[4] C.D. Collins, and M.E. Fryer, Model intercomparison for the uptake of organic chemicals by plants, Environ. Sci. Technol. 37 (2003), pp. 1617-1624; Erratum 37, pp. 3038.

[5] E. Undeman, G. Czub, and M.S. McLachlan, Addressing Temporal Variability When Modeling Bioaccumulation in Plants, Environ. Sci. Technol. 43 (2009), pp. 37513756.

[6] S. Trapp, C. McFarlane, and M. Matthies, Model for uptake of xenobiotics into plants - validation with bromacil experiments, Environ. Toxicol. Chem. 13 (1994), pp. 413422.

[7] S. Trapp, and M. Matthies, Generic one-compartment model for uptake of organicchemicals by foliar vegetation, Environ. Sci. Technol. 29 (1995), pp. 2333-2338; Erratum 30, pp. 360.

[8] S. Trapp, Dynamic root uptake model for neutral lipophilic organics, Environ. Toxicol. Chem. 21 (2002), pp. 203-206.

[9] S. Trapp, Fruit Tree model for uptake of organic compounds from soil and air, SAR QSAR Environ. Res. 18 (2007), pp. 367-387.

[10] S. Trapp, Legind, C.N., Uptake of organic contaminants from soil into vegetables and fruit, in Dealing with Contaminated Sites: From Theory towards Practical Application, F. Swartjes, ed., Springer, Dordrecht, in press.

[11] S. Paterson, D. Mackay, and C. McFarlane, A model of organic-chemical uptake by plants from soil and the atmosphere, Environ. Sci. Technol. 28 (1994), pp. 22592266.

[12] R. Juraske, F. Castells, A. Vijay, P. Munoz, and A. Anton, Uptake and persistence of pesticides in plants: Measurements and model estimates for imidacloprid after foliar and soil application, J. Hazard. Mater. 165 (2009), pp. 683-689.

[13] T. Fujisawa, K. Ichise, M. Fukushima, T. Katagi, and Y. Takimoto, Mathematical model of the uptake of non-ionized pesticides by edible root of root crops, J. Pestic. Sci. 27 (2002), pp. 242-248.

[14] T. Fujisawa, K. Ichise, M. Fukushima, T. Katagi, and Y. Takimoto, Improved uptake models of nonionized pesticides to foliage and seed of crops, J. Agric. Food. Chem. 50 (2002), pp. 532-537.

[15] S. Trapp, A. Cammarano, E. Capri, F. Reichenberg, and P. Mayer, Diffusion of PAH in potato and carrot slices and application for a potato model, Environ. Sci. Technol. 41 (2007), pp. 3103-3108.

[16] L.C. Paraiba, Pesticide bioconcentration modelling for fruit trees, Chemosphere 66 (2007), pp. 1468-1475.

[17] L.C. Paraiba, and K. Kataguiri, Model approach for estimating potato pesticide bioconcentration factor, Chemosphere 73 (2008), pp. 1247-1252. 
[18] H. Hung, and D. Mackay, A novel and simple model of the uptake of organic chemicals by vegetation from air and soil, Chemosphere 35 (1997), pp. 959-977.

[19] M. Severinsen, and T. Jager, Modelling the influence of terrestrial vegetation on the environmental fate of xenobiotics, Chemosphere 37 (1998), pp. 41-62.

[20] S.C. Bloch, Excel for engineers and scientists, John Wiley, New York, 2003.

[21] S. Trapp, and M. Matthies, Chemodynamics and environmental modeling: An introduction, Springer, Berlin-Heidelberg, 1998.

[22] F.J. Richards, A flexible growth function for empirical use, J. Exp. Bot. 10 (1959), pp. 290-300.

[23] S. Trapp, A.S. Ucisik, P. DelChica Romano, and M. Larsen, The Role of Plants and Bacteria in Phytoremediation - Kinetic Aspects, in Bioremediation of Soils Contaminated with Aromatic Compounds, H. J. Heipieper, ed., Springer, Berlin, 2007, pp. 41-49.

[24] W. Larcher, Physiological plant ecology, 3 ed, Springer, Berlin, 1995.

[25] R.H. Bromilow, and K. Chamberlain, Principles governing uptake and transport of chemcials, in Plant Contamination, S. Trapp and C. McFarlane, eds., Lewis Publishers, London, Tokio, 1995, pp. 37-68.

[26] C.N. Legind, C.M. Kennedy, A. Rein, N. Snyder, and S. Trapp, Dynamic plant uptake model applied for drip irrigation of an insecticide to pepper fruit plants (subm. to Pest Manag. Sci.).

[27] EC, EUSES, the European Union System for the Evaluation of Substances, National Institute of Public Health and the Environment (RIVM), The Netherlands, 1996.

[28] G. Rippen, Handbuch Umweltchemikalien, Ecomed, Landsberg am Lech, Germany, 2000.

[29] I. Elmadfa, Aign, W., Muskat, E., Fritsche, D., Cremer, H.D., Die große GU Nährwert Tabelle, Gräfe und Unzer, Giessen, Germany, 1991.

[30] J. Köhnlein, and H. Vetter, Ernterückstände und Wurzelbild, Verlag Parey, BerlinHamburg, 1953.

[31] W.W. Wilhelm, Dry-matter partitioning and leaf area of winter-wheat grown in a long-term fallow tillage comparisons in the US Central Great Plains, Soil \& Tillage Research 49 (1998), pp. 49-56.

[32] S. Asseng, N.C. Turner, T. Botwright, and A.G. Condon, Evaluating the impact of a trait for increased specific leaf area on wheat yields using a crop simulation model, Agron. J. 95 (2003), pp. 10-19.

[33] J. Quade, Faustzahlen für Landwirtschaft und Gartenbau, 12th ed, Landwirtschaftsverlag GmbH, Bochum, Germany, 1993.

[34] ECHA, Guidance on information requirements and chemical safety assessment, European Chemicals Agency, 2008. Available at http://echa.europa.eu/reach_en.asp.

[35] S. Trapp, Model for Uptake of Xenobiotics into Plants., in Plant Contamination, S. Trapp and C. McFarlane, eds., Lewis Publishers, London, Tokio, 1995, pp. 107-151.

[36] D.A. Kleier, Phloem mobility of xenobiotics - I. Mathematical model unifying the weak acid and intermediate permeability., Plant Physiol. 86 (1988), pp. 803-810.

[37] D. Frohne, and U. Jensen, Systematik des Pflanzenreiches unter besonderer Berücksichtigung chemischer Merkmale und pflanzlicher Drogen, Vol. 9, Gustav Fischer, Stuttgart, Germany, 1985.

[38] J.C. Zadoks, T.T. Chang, and C.F. Konzak, Decimal code for growth stages of cereals, Weed Res. 14 (1974), pp. 415-421.

[39] E.L. Wang, and T. Engel, Simulation of phenological development of wheat crops, Agricultural Systems 58 (1998), pp. 1-24. 
[40] M.Z. Kang, J.B. Evers, J. Vos, and P. De Reffye, The derivation of sink functions of wheat organs using the GREENLAB model, Ann. Bot. 101 (2008), pp. 1099-1108.

[41] S.R. Simmons, E.A. Oelke, and P.M. Anderson, Growth and development guide for spring wheat, in Univ. Minn. Agr. Ext. Folder, University of Minnesota, 1995.

[42] S. Demotes-Mainard, and M.H. Jeuffroy, Incorporating radiation and nitrogen nutrition into a model of kernel number in wheat, Crop Sci. 41 (2001), pp. 415-423.

[43] S.C. Tripathi, K.D. Sayre, J.N. Kaul, and R.S. Narang, Lodging behavior and yield potential of spring wheat (Triticum aestivum L.): effects of ethephon and genotypes, Field Crops Res. 87 (2004), pp. 207-220. 


\section{Tables}

Table 1. Mass balance equations for change of compound mass $m$ in root, stem, leaves and fruits (indices $R, S t, L$ and $F$ ) with time $t$.

$$
\begin{array}{lll}
\text { Root } \frac{d m_{R}}{d t}=Q \times K_{W S} \times C_{S}-\frac{Q}{K_{R W}} \times C_{R}-k_{R, \mathrm{deg}} \times m_{R} & 6 \mathrm{a} \\
\text { Root } \quad \frac{d m_{R, \text { diff }}}{d t}=1000 \times A_{R} P_{R} \times K_{W S} C_{S}-1000 \frac{A_{R} P_{R}}{K_{R W}} C_{R} & 6 \mathrm{~b} \\
\text { Stem } \quad \frac{d m_{S t}}{d t}=\frac{Q}{K_{R W}} C_{R}-\frac{Q}{K_{S t W}} C_{S t}+\frac{A_{S t} P_{S t}}{K_{A W}} C_{A} \times\left(1-f_{P}\right)+A_{S t} v_{d e p} C_{A} \times f_{P} & \\
-1000 \frac{A_{S t} P_{S t}}{K_{S t W}} C_{S t}-k_{S t, \mathrm{deg}} m_{S t} & \frac{Q_{L}}{K_{L}} C_{S t}+\frac{A_{L} P_{L}}{K_{A W}} C_{A} \times\left(1-f_{P}\right)+A_{L} v_{d e p} C_{A} \times f_{P}-1000 \frac{A_{L} P_{L}}{K_{L W}} C_{L}-k_{L, \mathrm{deg}} m_{L} & 8 \\
\text { Leaf } \quad \frac{d m_{F}}{d t}=\frac{Q_{F}}{K_{S t W}} C_{S t}+\frac{A_{F} P_{F}}{K_{A W}} C_{A} \times\left(1-f_{P}\right)+A_{F} v_{d e p} C_{A} \times f_{P}-1000 \frac{A_{F} P_{F}}{K_{F W}} C_{F}-k_{F, \mathrm{deg}} m_{F} & 9
\end{array}
$$

Notes: Equation $6 \mathrm{~b}, \mathrm{~d} m_{R, \text { diff }} / \mathrm{d} t$ : mass balance describing solely diffusion into/out of the roots; $C$ : concentration $\left(\mathrm{mg} \mathrm{kg}^{-1}\right)$ in the plant compartments, in soil $\left(C_{S}\right)$ and in air $\left(C_{A}, \mathrm{mg} \mathrm{m}^{-3}\right) ; Q$ : transpiration $\left(\mathrm{L} \mathrm{d}^{-1}\right) ; A$ : surface area $\left(\mathrm{m}^{2}\right) ; P$ : permeability $\left(\mathrm{m} \mathrm{d}^{-1}\right) ; K_{A W}$ : air-water partition coefficient $\left(\mathrm{L} \mathrm{L}^{-1}\right) ; K_{W S}$ : partition coefficient between water and soil $\left(\mathrm{kg} \mathrm{L}^{-1}\right), K_{i W}$ : partition coefficients $\left(\mathrm{L} \mathrm{kg}^{-1}\right)$ between plant compartment $i$ and water, details see [9]; $k_{i, d e g}$ : first-order degradation rate constant $\left(\mathrm{d}^{-1}\right)$ in plant compartment $i$; $f_{P}$ : fraction of particles $(-), v_{\text {dep }}$ : particle deposition velocity $\left(\mathrm{m} \mathrm{d}^{-1}\right)$ [21]. 
Table 2. Soil input data and physicochemical properties.

\begin{tabular}{|c|c|c|c|c|}
\hline Parameter & Symbol & Value & Unit & Reference \\
\hline \multicolumn{5}{|c|}{ Physicochemical parameters of trichloroethene (TCE) } \\
\hline Molar mass & $M_{W}$ & 131.39 & $\mathrm{~g} \mathrm{~mol}^{-1}$ & [28] \\
\hline Octanol-water partition coeff. (log) & $\log K_{\text {ow }}$ & 2.42 & - & [28] \\
\hline Air-water partition coefficient & $K_{A W}$ & 0.403 & $L L^{-1}$ & [28] \\
\hline \multicolumn{5}{|l|}{ Soil input data } \\
\hline Soil water content & $w_{s}$ & 0.35 & $L L^{-1}$ & Danish reference soil \\
\hline Soil gas pores & $G_{S}$ & 0.1 & $L L^{-1}$ & Danish reference soil \\
\hline Content of soil organic carbon & OC & 0.02 & $\mathrm{~g} \mathrm{~g}^{-1}$ & [27] \\
\hline Dry soil density & $\rho_{S, d r y}$ & 1.6 & $\mathrm{~kg} \mathrm{~L}^{-1}$ & Danish reference soil \\
\hline Degradation rate in soil & $k_{S, \text { deg }}$ & 0 & $d^{-1}$ & Generic \\
\hline
\end{tabular}


Table 3. Size-independent plant parameters.

\begin{tabular}{llrcl}
\hline Parameter & Symbol & Value & Unit & Reference \\
\hline Transpiration coefficient & $T_{C}$ & 500 & $\mathrm{~L} \mathrm{~kg}^{-1}(\mathrm{dw})$ & {$[24]$} \\
Diffusion length, aq. boundary layer & $d_{x}$ & $5 \times 10^{-4}$ & $\mathrm{~m}$ & Generic \\
Relative air humidity & $r h$ & 0.5 & - & Generic \\
Temperature & $T$ & 20 & ${ }^{\circ} \mathrm{C}$ & Generic \\
Root degradation rate constant & $k_{R, \text { deg }}$ & 0 & $\mathrm{~d}^{-1}$ & Generic \\
Root water content & $W_{R}$ & 0.89 & $\mathrm{~g} \mathrm{~g}^{-1}$ & {$[29]$} \\
Root lipid content & $L_{R}$ & 0.025 & $\mathrm{~g} \mathrm{~g}^{-1}$ & {$[8]$} \\
Root gas pores & $G_{R}$ & 0.1 & $\mathrm{~L} \mathrm{~L}^{-1}$ & {$[8]$} \\
Root bulk density & $\rho_{R}$ & 1 & $\mathrm{~kg} \mathrm{~L}^{-1}$ & Generic \\
Stem degradation rate constant & $k_{S t, d e g}$ & 0 & $\mathrm{~d}^{-1}$ & Generic \\
Stem water content & $W_{S t}$ & 0.8 & $\mathrm{~g} \mathrm{~g}^{-1}$ & See leaves \\
Stem lipid content & $L_{S t}$ & 0.02 & $\mathrm{~g} \mathrm{~g}^{-1}$ & See leaves \\
Stem bulk density & $\rho_{S t}$ & 0.5 & $\mathrm{~kg} \mathrm{~L}^{-1}$ & See leaves \\
Leaf degradation rate constant & $k_{L, d e g}$ & 0 & $\mathrm{~d}^{-1}$ & Generic \\
Leaf water content & $W_{L}$ & 0.8 & $\mathrm{~g} \mathrm{~g}^{-1}$ & {$[7]$} \\
Leaf lipid content & $L_{L}$ & 0.02 & $\mathrm{~g} \mathrm{~g}^{-1}$ & {$[7]$} \\
Leaf bulk density & $\rho_{L}$ & 0.5 & $\mathrm{~kg} \mathrm{~L}^{-1}$ & Generic \\
Corn degradation rate constant & $k_{F, \text { deg }}$ & 0 & $\mathrm{~d}^{-1}$ & Generic \\
Corn water content & $W_{F}$ & 0.5 & $\mathrm{~g} \mathrm{~g}^{-1}$ & Average \\
Corn lipid content & $L_{F}$ & 0.02 & $\mathrm{~g} \mathrm{~g}^{-1}$ & See leaves \\
Corn bulk density & $\rho_{F}$ & 1 & $\mathrm{~kg} \mathrm{~L}^{-1}$ & Generic \\
\hline
\end{tabular}


Table 4. Size-dependent and growth-related plant parameters, normalised to $1 \mathrm{~m}^{2}$ field; $\mathrm{dw}$ is dry weight, App. is Appendix.

\begin{tabular}{|c|c|c|c|c|}
\hline Parameter & Symbol & Value & Unit & Reference \\
\hline \multicolumn{5}{|l|}{ Carrots ( = root) } \\
\hline Initial root mass & $M_{R, O}$ & 0.001 & $\mathrm{~kg}(\mathrm{dw})$ & App. 3 \\
\hline Final root mass & $M_{R, \max }$ & 1 & $\mathrm{~kg}(\mathrm{dw})$ & App. 3 \\
\hline Root growth rate constant & $k_{R}$ & 0.1 & $d^{-1}$ & App. 3 \\
\hline Final root radius & $r_{R}$ & 0.015 & $\mathrm{~m}$ & App. 3 \\
\hline Number of carrots & $n$ & 36 & - & App. 3 \\
\hline \multicolumn{5}{|l|}{ Spring wheat } \\
\hline Initial root mass & $M_{R, O}$ & 0.0025 & $\mathrm{~kg}(\mathrm{dw})$ & App. 1 \\
\hline Final root mass & $M_{R, \max }$ & 0.25 & $\mathrm{~kg}(\mathrm{dw})$ & [30] \\
\hline Root growth rate constant & $k_{R}$ & 0.075 & $d^{-1}$ & App. 1 \\
\hline Initial stem mass & $M_{S t, 0}$ & 0.00125 & $\mathrm{~kg}(\mathrm{dw})$ & App. 1 \\
\hline Final stem mass & $M_{S t, \max }$ & 0.45 & $\mathrm{~kg}(\mathrm{dw})$ & App. 1 \\
\hline Stem growth rate constant & $k_{S t}$ & 0.08 & $d^{-1}$ & App. 1 \\
\hline Specific stem area & SStA & 10 & $\mathrm{~m}^{2} \mathrm{~kg}^{-1}(\mathrm{dw})$ & App. 1 \\
\hline Initial leaf mass & $M_{L, 0}$ & 0.00125 & $\mathrm{~kg}(\mathrm{dw})$ & App. 1 \\
\hline Final leaf mass & $M_{L, \max }$ & 0.05 & $\mathrm{~kg}(\mathrm{dw})$ & [31] \\
\hline Leaf growth rate constant & $k_{L}$ & 0.08 & $d^{-1}$ & App. 1 \\
\hline Specific leaf area & $S L A$ & 30 & $\mathrm{~m}^{2} \mathrm{~kg}^{-1}(\mathrm{dw})$ & {$[32]$} \\
\hline Initial corn mass & $M_{F, O}$ & $5.6 \times 10^{-6}$ & $\mathrm{~kg}(\mathrm{dw})$ & App. 1 \\
\hline Final corn mass & $M_{F, \max }$ & 0.56 & $\mathrm{~kg}(\mathrm{dw})$ & [33] \\
\hline Corn growth rate constant & $k_{F}$ & 0.14 & $d^{-1}$ & App. 1 \\
\hline Specific corn area & $S C A$ & 2 & $\mathrm{~m}^{2} \mathrm{~kg}^{-1}(\mathrm{dw})$ & App. 1 \\
\hline
\end{tabular}




\section{Figure captions}

Figure 1. Different input functions and their consequence for the resulting concentration time course. a) Repeated pulse input plus constant background, b) input from quasi-constant external source (changing at $t=30$ units), c) irregular, variable input function $I$ and resulting concentration $C$.

Figure 2. Simulated growth and transpiration of spring wheat. $M$ : total plant mass (dry weight dw), $Q$ : transpiration in roots and stem, $Q_{L}$ : transpiration in leaves, $Q_{F}$ : transpiration plus phloem flux to fruits.

Figure 3. Structure of the Multi-Cascade crop model, with transfer rate constants $k_{i j}\left(\mathrm{~d}^{-1}\right)$ (transfer from compartment $i$ to $j$ ), total loss rate constant $k_{i}\left(\mathrm{~d}^{-1}\right)$, constant external input $b$ $\left(\mathrm{mg} \mathrm{kg}^{-1} \mathrm{~d}^{-1}\right)$.

Figure 4. Modelled chemical uptake into carrot considering advection (adv), diffusion (diff) and advection plus diffusive uptake ( $\mathrm{adv}+$ diff). a) and b): TCE mass and concentration as a function of time, c): concentrations vs. $\log K_{O W}$ (hypothetical compounds with varying $\log$ $K_{O W}, K_{A W}=1$ ) at harvest time (day 150). $C(\infty)$ exp-gr: steady-state concentration for exponential growth and advective uptake, $C(\infty)$ non-gr: steady-state concentration under conditions without growth.

Figure 5. Dynamics of TCE uptake into spring wheat in comparison to steady-state, simulated concentrations in root and stem (a) and leaf and corn (b). $C_{i}(\infty)$ exp: steady-state concentration for exponential growth.

Figure 6. Steady-state and dynamic concentrations vs. $\log K_{O W}$ for root (a), stem (b), leaf (c) and corn (d to h). e) to h): different $K_{A W}$ values for corn. Dynamic results $C(t)$ at time $t=30$ (exponential growth phase) and $150 \mathrm{~d}$ (at harvest, after ripening), steady-state results 
referring to the phase of exponential growth $\left(C_{\exp }(o o)\right)$ and ripening $\left(C_{\text {rip }}(o o)\right.$, growth nearly zero).

Figure 7. Example results obtained with the Multi-Cascade model ( $C$ casc) for different period lengths $\Delta t_{p}$, in comparison to numerical calculations $(C n u m)$ for TCE uptake, concentrations in a) roots and stem, b) leaves and c) corn.

Figure 1.1. a): EC-stage versus time for spring wheat, filled diamonds: reported typical date, crosses: approximated date of EC-stages (best estimate). b) and c): Growth of spring wheat mass (dry weight dw), b): modelled vs. measured/approximated (measured dry weight, date approximated from EC-stage, see a), c): modelled root, stem, leaf and corn mass.

Figure 3.1. Simulated growth of carrots. a) volume $V_{R}$, length $l_{R}$ and radius $\left.r_{R}, \mathrm{~b}\right)$ area $A_{R}$, mass $M_{R}$ and transpiration stream $Q$, c) ratios $l_{R} / r_{R}, A_{R} / M_{R}$ and $Q / M_{R}$ as a function of time. 

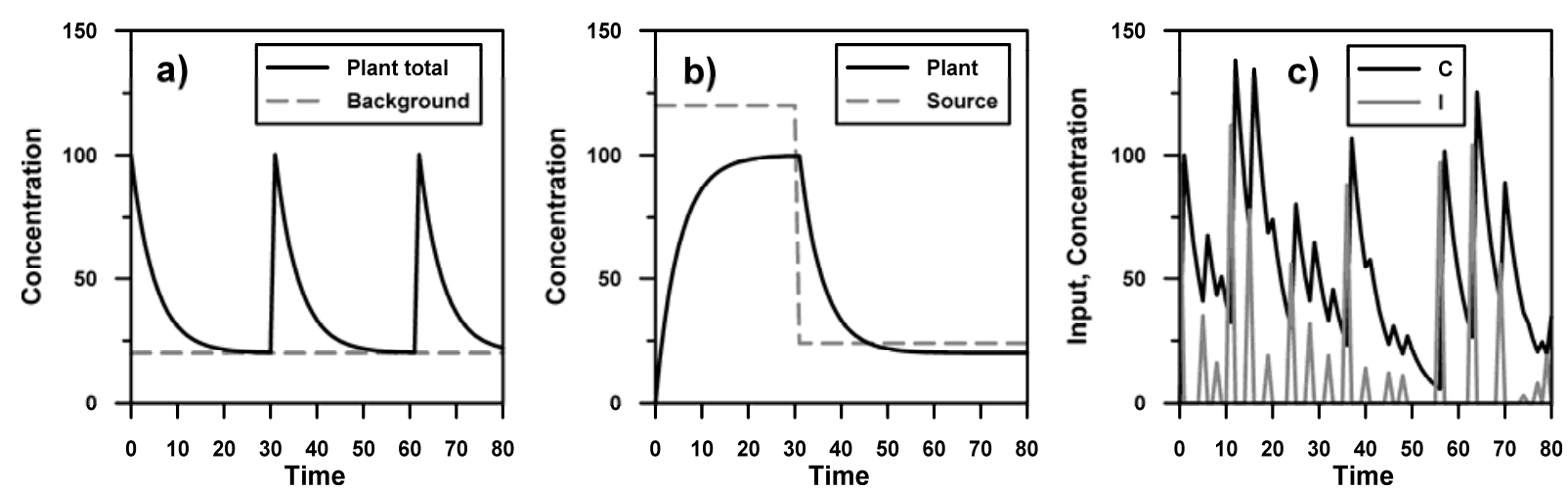

Figure 1 


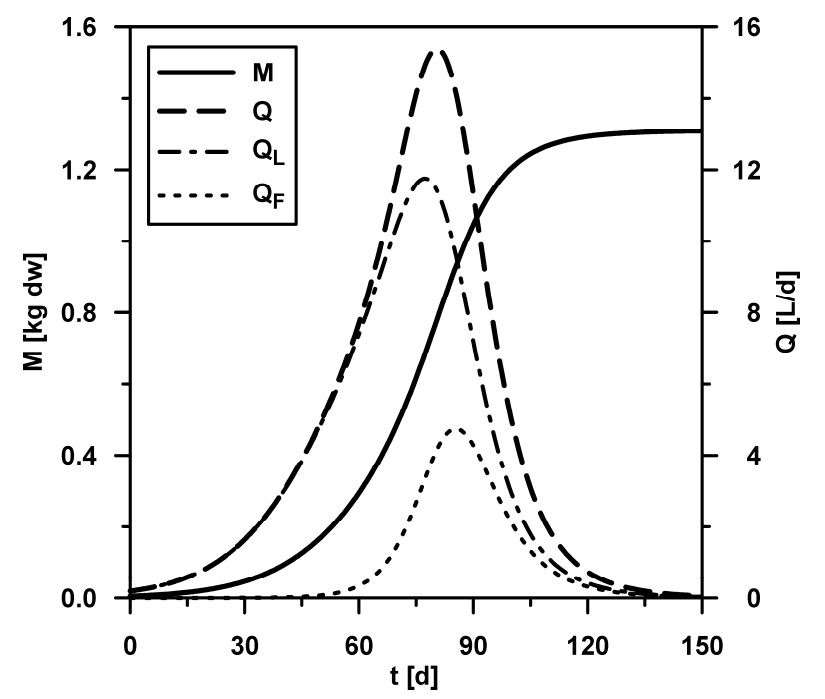

Figure 2 


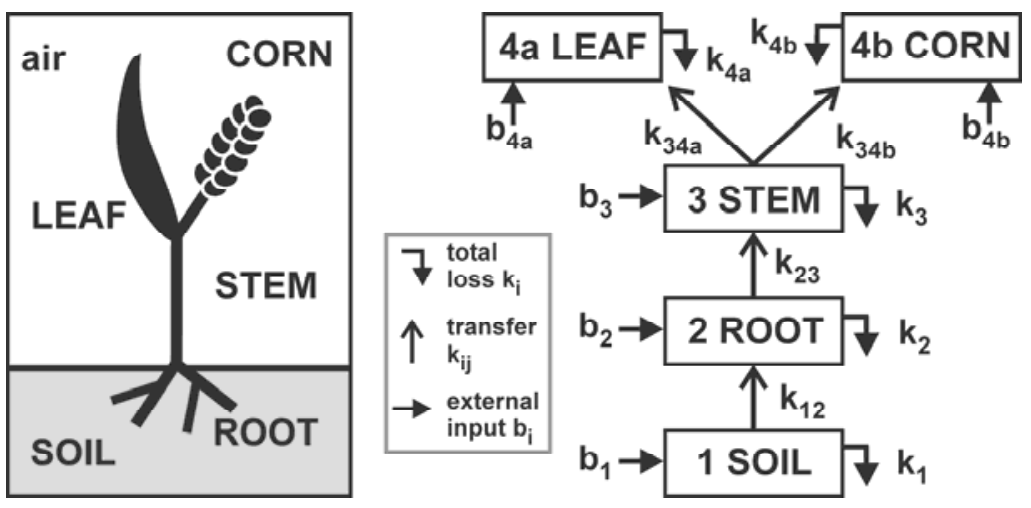

Figure 3 

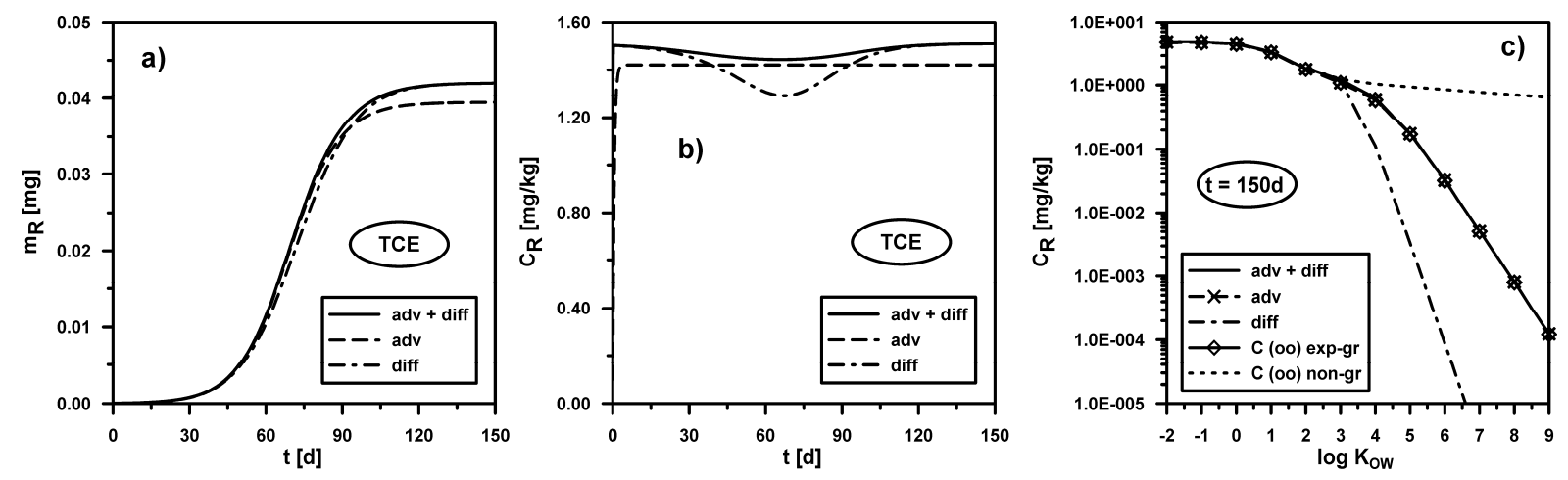

Figure 4 
A. Rein et al.

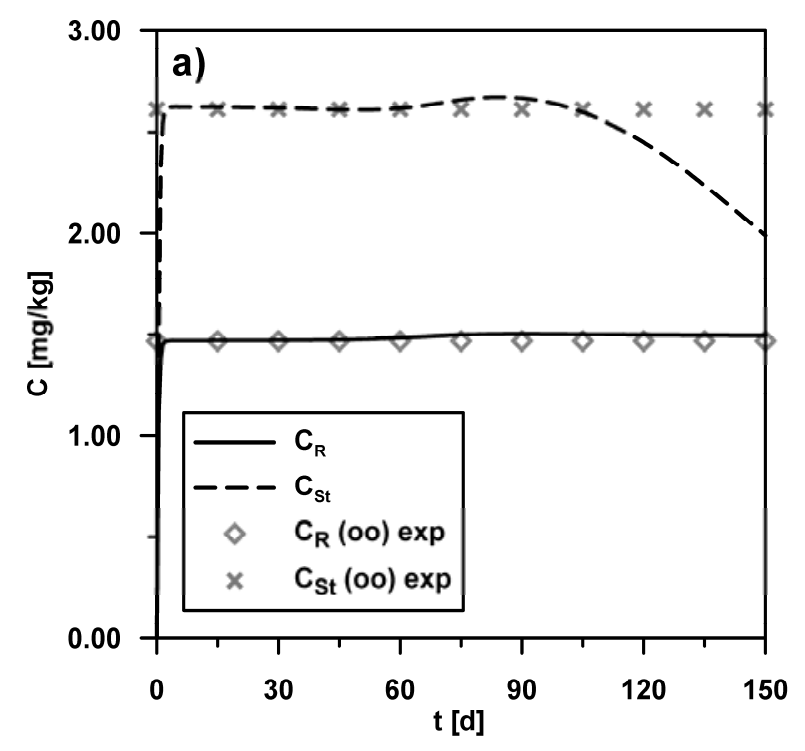

SAR and QSAR in Environmental Research

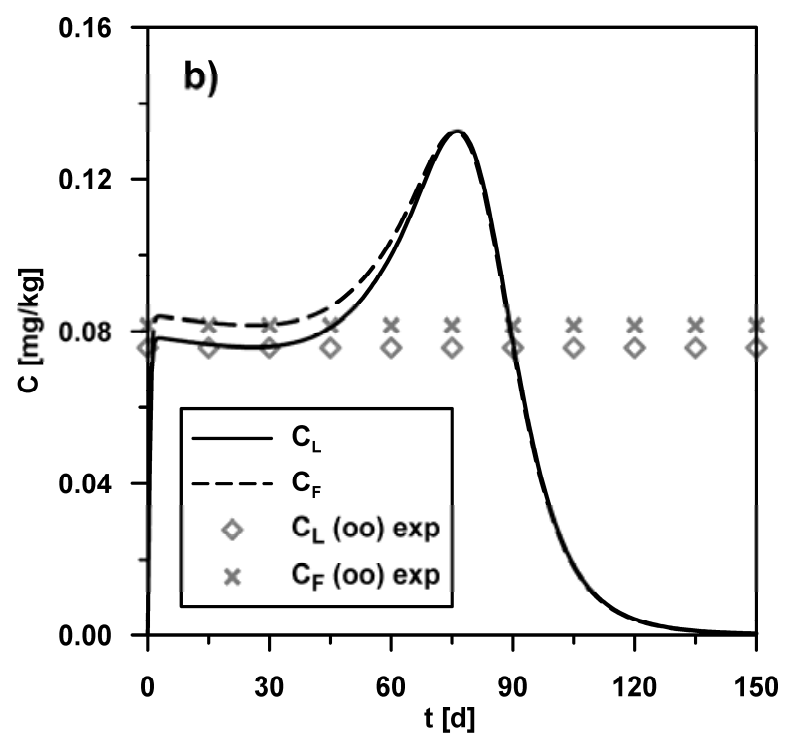

Figure 5 

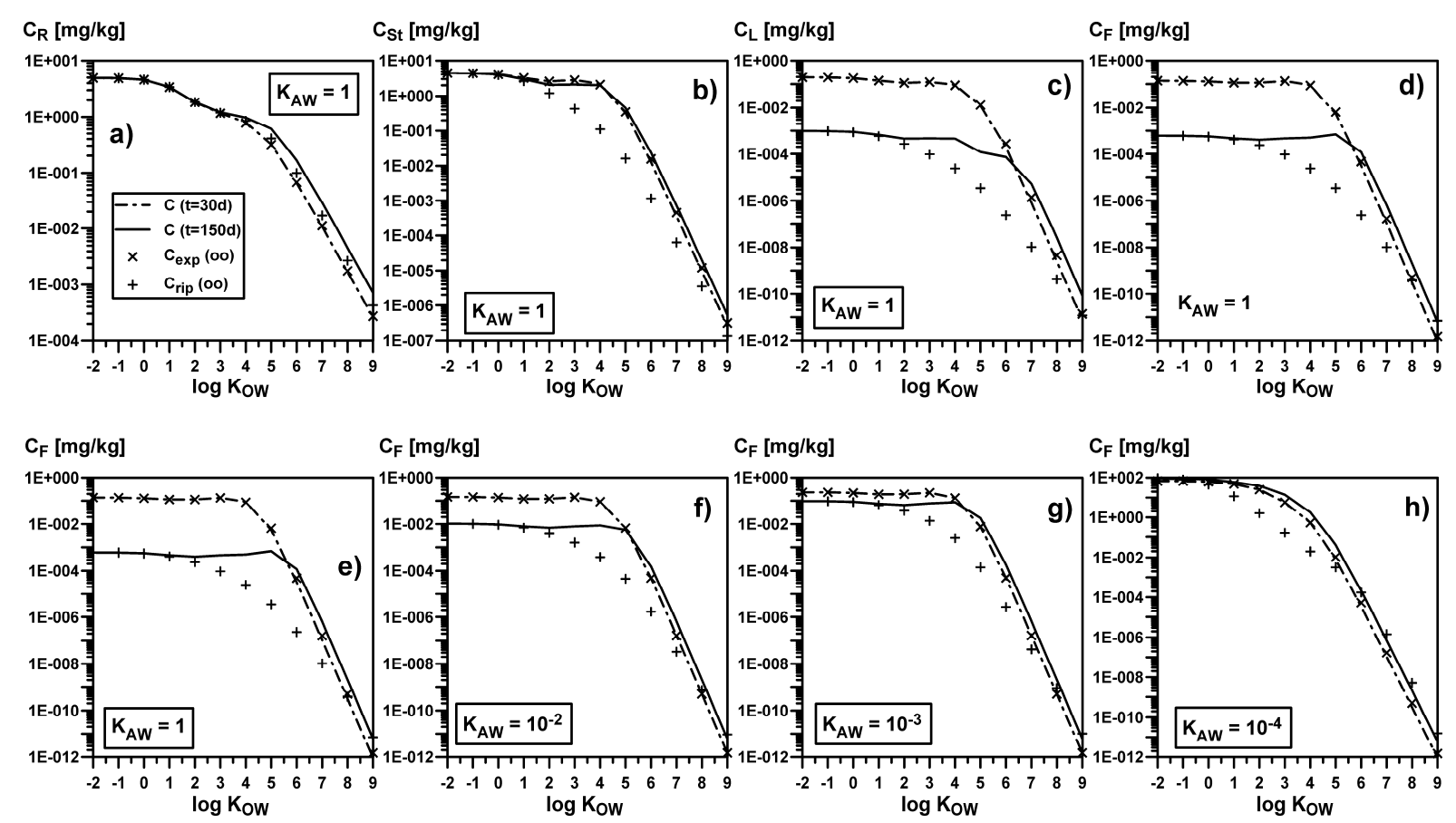

Figure 6 

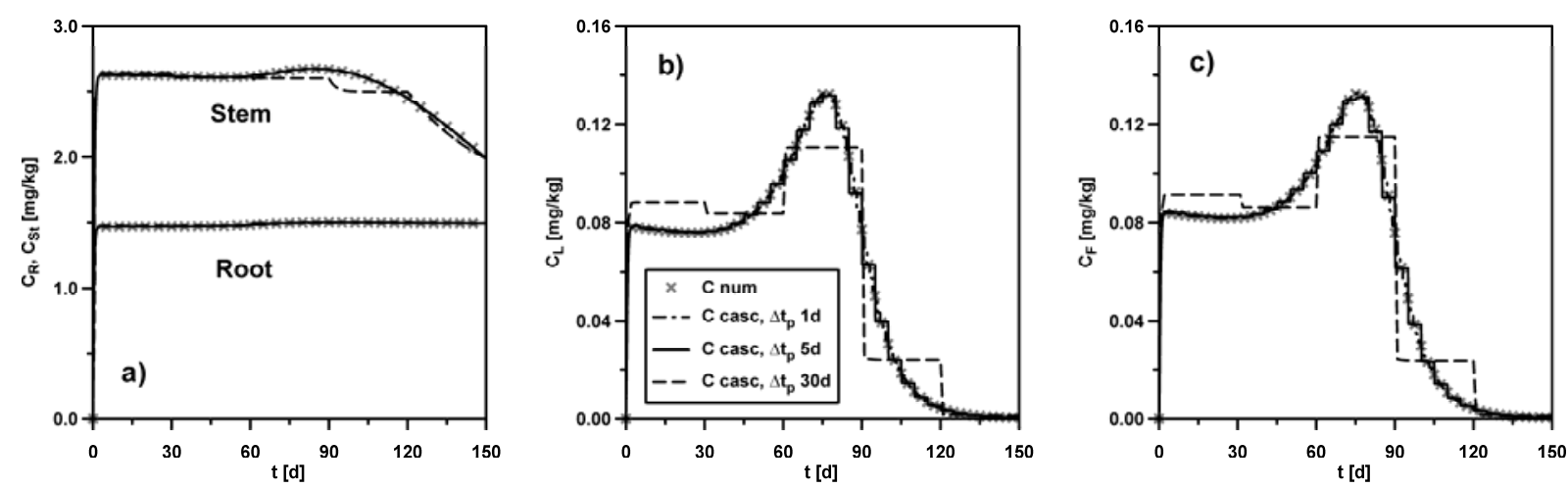

Figure 7 

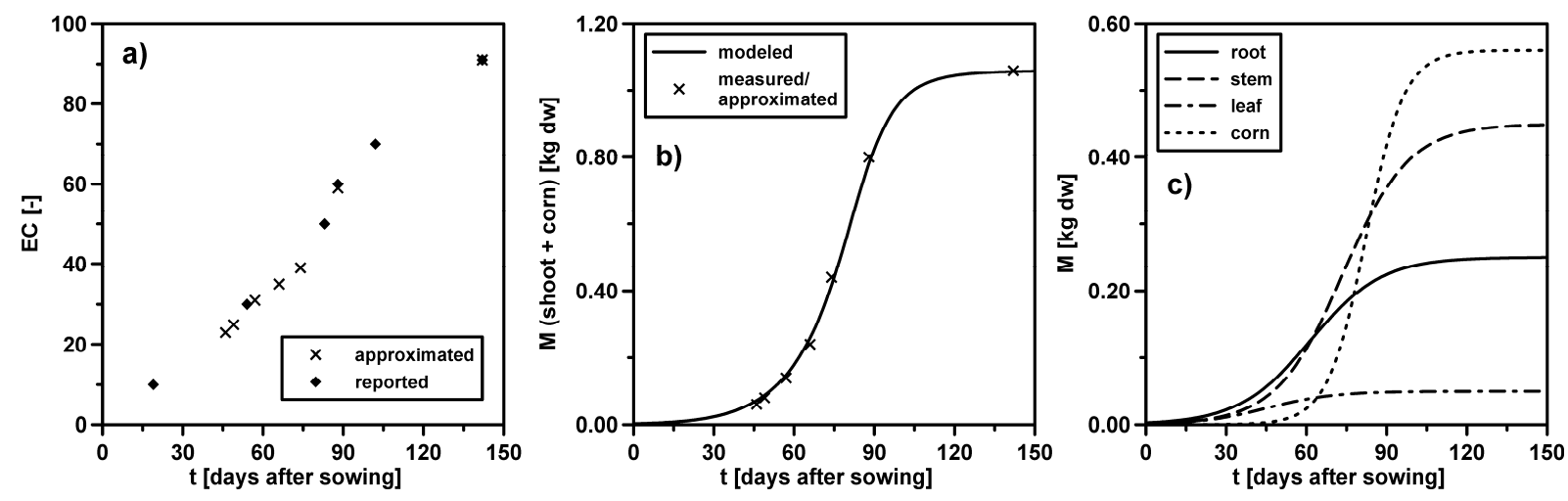

Figure 1.1 

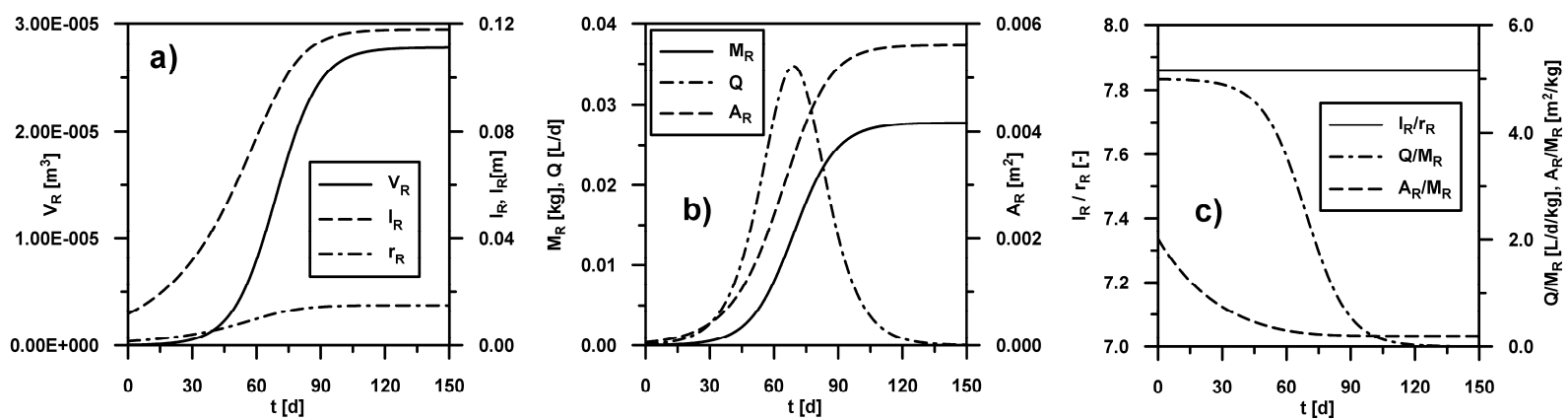

Figure 3.1 